\title{
The evaluation of agility in supply chain of mass construction associations in Iran: A case study of construction firm
}

\author{
Reza Kiani Mavi ${ }^{a}$, Seyed Majid Elahi Noghani ${ }^{\mathrm{b}}$, Safar Fazlib and Keyvan Poloie ${ }^{{ }^{*}}$
}

${ }^{a}$ Assistant Professor, Department of Industrial Management, Qazvin Islamic Azad University (QIAU), Qazvin, Iran

${ }^{b}$ Assistant Professor, Department of Industrial Management, Imam Khomeini International University (IKIU), Qazvin, Iran ${ }^{c}$ Department of Industrial Management, Imam Khomeini International University (IKIU), Qazvin, Iran

\begin{abstract}
A B S T R A C T
Survival of production systems has become complicated with the emergence of new areas in business. In other words, changes in business environment, which are the results of changes in customers' needs lead us to an uncertainty in making decisions; therefore there is a need to have a flexible supply chain to confront the changes. Agility is considered as a solution to enable mass construction associations to maintain in a competitive environment of housing industry in Iran. The aim of this study is to introduce a method to evaluate the agility of supply chain for mass construction associations. The proposed method of this paper designed questionnaires to evaluate the agility of supply chain based on identified criteria and indices. The questionnaires were filled by experts and scholars and then analyzed with SPSS software. Findings of this study show that the agility of the case study of this paper is ranked 2 out of 5 or $40 \%$. According to the evaluations of agility, the highest score goes to financial and the lowest score belongs to information technology.
\end{abstract}

\section{Introduction}

Traditional associations can be recognized by their properties such as building, machineries and stock since demands were more than supplies in a stable environment, but present business environments have been under changes which are:

1. Instability and variability of the market, which increase costs, competitiveness and short period development of new products in the market.

2. Changes in customers' demands are the consequences of customized demands, high quality expectations and faster deliveries. 
3. With integrating the software and hardware parts of a system, new and sufficient facilities will be engendered.

4. Changes in sociological factors because of the environmental considerations, labor expectations and legal pressures.

In a changing environment, attracting necessary costumers to have liquidity and profitability is required for survival of firms, and this can be achieved only when the firm has "Agility” or responses the needs, quickly. The need of response to customers' demands, changing environments and increase the environment's complexity has directed organizations towards the concept of "agility". Agility can be defined as "the ability to response to the unpredictable changes and supply the various demands of the costumers according to the prices, quality, quantity and delivery” (Prince \& Kay, 2003). Another definition is stated as "the ability to have reaction towards changes, and to have the power of predictability in business environment". Finally some people defined agility as "the ability to have flexibility towards new technologies" and "the ability to have reactions toward rules and regulations".

An essential index of organization's agility is agility in its supply chain, which causes the reduction of total time of supply chain. With the beginning of $21^{\text {st }}$ century, organizations and individuals have experienced new phenomena and events. The emergence of information technology in all the areas, the need of providing customers' needs, changing demands of the market and costumers, the movement towards physical and virtual network, the omission of wastes in organizations are the most important developments and innovations in management area. According to TUV NORD Institute, there have been problems in supply chain of Oil Company, which can be seen in supply chain of mass construction associations too. They are:

- The unavailable items,

- The long delivery time(both for material and building),

- Low efficiency of communication in supply chain,

- Low quality integration and coordination in supply chain,

- Problems of organizational culture,

- Lack of efficient organizational structure,

- Lack of clear strategies and supply chain's aims,

- Lack of adequate information exchange within different units of supply chain,

- Lack of evaluation system and proper monitoring,

- Poor management of suppliers,

- Stagnation of capital in large amount because of goods and raw materials' inertia.

Although necessity of agility in most industries cannot be denied, the Iranian mass construction associations do not regard agility as an essential element for the development of their supply chain. It should be noted that if companies apply agility in their supply chain, they will enjoy from benefits of it, which helps them predict and response to demands quickly. In this research we look to know how Iranian mass construction associations can evaluate agility in their supply chain. In the second part, we review the literature of the research. The third part explains methodology of the research and data gathering and development levels. Findings of the research are presented in the fourth part and finally we provide our conclusion and comments for further studies in the fifth part of this study.

\section{Theoretical Framework}

Unfortunately, agility can be explained as a general concept associated with construction and production (Maskell, 2001). One of the definitions of the term "agile production" can be found in a report under the name "Iaccocca". Definition of agility is referred to benefit from a competitive advantage in the production system (Rigby et al., 2000). Some people believe that the qualities of agility can be found through the production system and it seems that a broad focus of supply chain is 
more on proper evaluation of the qualities. Therefore, supply chain offers a more functional set to evaluate the qualities of agility than a conceptual approach does. This matter has been approved by Rigby et al, (2000) too. He claims there is no probability that an individual firm can be able to product with proper added value. Agility of supply chain means the ability of supply chain to response the changes of the market and customers' demands, which is a considerable advantage in today's business world (Christopher \& Towill, 2002; Gunasekaran et al., 2004; Yusuf et al., 2002). Agile supply chain tends to be flexible towards unpredictable changes of the market. It seeks to benefit from these changes by fast delivery and flexibility, and to achieve so, it applies technologies and new tools like advanced information technology, electronic data exchange and virtual networks (Vonderembse et al., 2006). A supply chain must have simultaneous outstanding characteristics as "market sensitivity”, "being virtually", "functionally integrated" and "being Network Based”. These features include the connections in agile supply chain and the use of information technology in activities (Kisperska-Moron \& Swierczek, 2008). The importance of the relation with business partners (costumers, suppliers, service providers and competitors) has been focused many times in scientific texts.

Ball et al. (1999) believe that integration in agile supply chain means cooperation among customers and suppliers, development of joint product, common system and mutual information (Ball et al., 1999). Christopher (2000) is among those who studied the concept of agility thoroughly and explained its features. Kazazi and Sohrabi (2010) reviewed the literature specified to agility of supply chain and its place in oil companies and have defined the concept of agility in the supply chain of Iran National Oil Company as well. They also identified the indices and components of the evaluation of the agility in supply chain and introduced the relation among indices. Azar et al. (2010) have conducted a research by reviewing the literature and seeking to compile a comprehensive model of agility in supply chain. With interviewing the experts, they found eleven major factors in agile supply chain. Kazazi and Sohrabi (2010) has introduced the indices of the evaluation of agility in supply chain and investigated the relations among them in his Ph.D. thesis.

Jasbi et al. (2010) has introduced different aspect of agility and the procedure to achieve the agility by associations. He also offered a way to evaluate the agility. Agarwal et al. (2007) used interpretive and structural modeling to show the relationships among the variables of agility in supply chain. They compared functions of three "agile", "lean" and "lean-agile” supply chains in another study. Radfar et al. (2011) provided a model to evaluate the agility of the supply chain in two prominent Iranian telecom companies and to prevent the ambiguities they used Fuzzy system. There have been other researches specific to agility in supply chain such as Tolone studies (2000), Svenson (2001) and Peter Baker (2008). In most of these studies, one aspect of agility has been chosen and examined, e.g. Wilding and Gondry (1999) emphasized on virtual groups to create agility.

\section{Research methodology}

To conduct this study, we first reviewed the literature to identify the indices and criteria of agility in supply chain. We used the indices and criteria of a study conducted by Poloie (2010). We designed questionnaires to determine the score of agility in supply chain of Misagh Merat Mass construction Associations by gathering 110 experts' feedbacks. Among 110 filled questionnaires, 95 of them were completed and evaluation of agility was based on completed ones. Respondents were chosen among the scholars and experts of Misagh Merat Association. To analyze the findings, we used Excel and SPSS and questionnaires were filled according to Table 1.

\section{Table 1}

Guidance to answer the questionnaire of evaluation the agility in supply chain

\begin{tabular}{cccccc}
\hline Score & 1 & 2 & 3 & 4 & 5 \\
\hline Verbal term & Very weak & Weak & Average & Good & Very Good \\
\hline
\end{tabular}


Misagh Merat Mass Construction Association was established in 2007 with the aim of constructing commercial, administrative, clerical buildings and complexes and also conducting projects such as roads, bridges, dams construction by using the services of professional agencies.

\subsection{Reliability and validity of data}

Evaluation tool must be reliable and valid to gather the proper finding in accordance with the research and by analyzing the findings and data answer the research questions. Evaluation tools are valid and reliable appropriately, so researchers can trust and apply them. However, a tool made by researcher suffers from the lack of trust and must assure the researcher with its validity and reliability.

\subsection{Validity of the measure tool}

By validity, we mean that the tool measures the variables accurately, and the gathered data are sufficient. The survey must be reliable, which means they must be accurate and consistent. In other words, reliable tool is a kind of tool which has a characteristic of repeatability with same results in a comparable situation. The validity of the questionnaire has been evaluated by SPSS software (Cronbach's Alpha) which will be presented in fourth part of this study. The proposed model of this paper uses a questionnaire to gather the necessary data and applies some weights as follows,

$\mathrm{ASC}=\mathrm{W}_{\mathrm{j}} \times \mathrm{S}_{\mathrm{j}}$

ASC: Agile Supply Chain

Wj: Criterion/index weight

$\mathrm{Sj}$ : Criterion/index score in the system

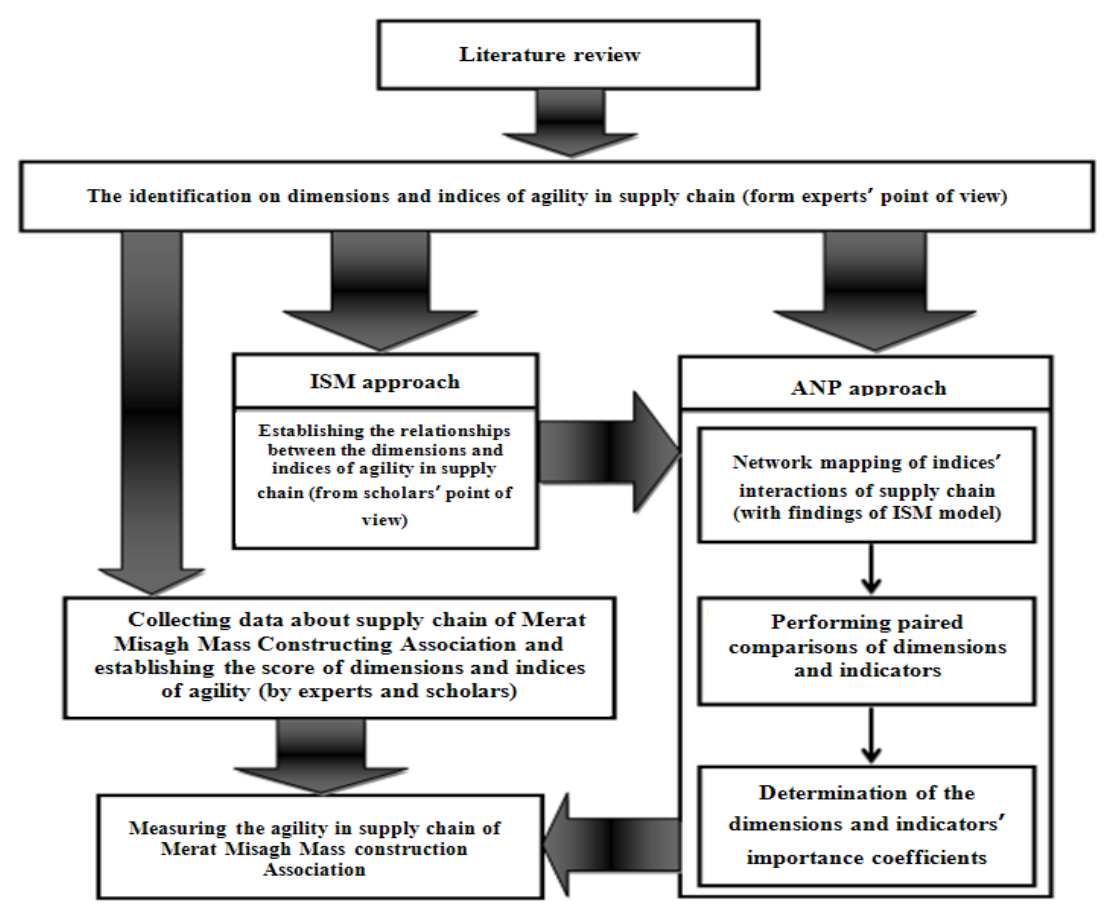

Fig. 1. The general function of the study (poloie, 2012)

\section{Findings}

Here, we offer the importance coefficient and indices of agility in supply chain identified by Poloei in his thesis in order to evaluate agility score of Misagh Merat Mass Association (Table 2). 
Table 2

Importance coefficient of criteria and indices of agility in mass construction associations

\begin{tabular}{|c|c|c|c|c|c|c|c|}
\hline index & $\begin{array}{l}\text { The initial } \\
\text { weight }\end{array}$ & $\begin{array}{l}\text { The normalized } \\
\text { weight }\end{array}$ & rank & Ranking criteria & criterion & weight & rank \\
\hline Market sensitivity & 0.044 & 0.058 & 7 & 3 & \multirow{4}{*}{ Market } & \multirow{4}{*}{0.223} & \multirow{4}{*}{1} \\
\hline Customer's satisfaction & 0.062 & 0.081 & 4 & 1 & & & \\
\hline Building's price & 0.048 & 0.063 & 6 & 2 & & & \\
\hline Building's location & 0.015 & 0.019 & 16 & 4 & & & \\
\hline Cost effectiveness & 0.087 & 0.115 & 2 & 1 & \multirow{3}{*}{ Technology } & \multirow{3}{*}{0.212} & \multirow{3}{*}{2} \\
\hline $\begin{array}{l}\text { Improvement of } \\
\text { designing and } \\
\text { construction }\end{array}$ & 0.035 & 0.047 & 10 & 3 & & & \\
\hline $\begin{array}{l}\text { Reduction of } \\
\text { constructing time }\end{array}$ & 0.038 & 0.050 & 9 & 2 & & & \\
\hline $\begin{array}{l}\text { Level of building's } \\
\text { owners }\end{array}$ & 0.015 & 0.020 & 15 & 1 & \multirow{3}{*}{ Society } & \multirow{3}{*}{0.033} & \multirow{3}{*}{4} \\
\hline culture & 0.003 & 0.004 & 22 & 3 & & & \\
\hline HSE & 0.006 & 0.008 & 21 & 2 & & & \\
\hline regulation & 0.110 & 0.146 & 1 & 1 & Government & 0.146 & 5 \\
\hline Accuracy of information & 0.009 & 0.011 & 19 & 2 & \multirow{2}{*}{$\begin{array}{l}\text { Information } \\
\text { technology }\end{array}$} & \multirow[b]{2}{*}{0.035} & \multirow[b]{2}{*}{8} \\
\hline $\begin{array}{l}\text { Integration of } \\
\text { information }\end{array}$ & 0.017 & 0.023 & 14 & 1 & & & \\
\hline $\begin{array}{l}\text { On time budget } \\
\text { providing }\end{array}$ & 0.055 & 0.073 & 5 & 1 & \multirow{4}{*}{ Financial } & \multirow{4}{*}{0.155} & \multirow{4}{*}{3} \\
\hline Infrastructure investment & 0.044 & 0.053 & 8 & 2 & & & \\
\hline $\begin{array}{l}\text { Financial ability of } \\
\text { customer }\end{array}$ & 0.013 & 0.017 & 18 & 3 & & & \\
\hline $\begin{array}{l}\text { Financial ability of } \\
\text { Contractor }\end{array}$ & 0.008 & 0.011 & 20 & 4 & & & \\
\hline Logistic flexibility & 0.023 & 0.031 & 12 & 1 & \multirow{3}{*}{ Partnership } & \multirow{3}{*}{0.072} & \multirow{3}{*}{7} \\
\hline Quick problem solving & 0.013 & 0.0177 & 17 & 3 & & & \\
\hline Strategic relations & 0.018 & 0.024 & 13 & 2 & & & \\
\hline $\begin{array}{l}\text { The adaptation level of } \\
\text { designing with } \\
\text { construction }\end{array}$ & 0.024 & 0.032 & 11 & 2 & \multirow[t]{2}{*}{ Quality } & \multirow[t]{2}{*}{0.120} & \multirow[t]{2}{*}{6} \\
\hline Construction quality & 0.067 & 0.088 & 3 & 1 & & & \\
\hline
\end{tabular}

As we can observe from the results of Table 2, "market" is the most important criterion and "information technology" is the least important one. Among the indices, "regulations" is the most and "culture" is the least important one. The relative importance of indices related to each criterion is shown in this table too.

\subsection{Reliability of assessment tools}

By using the literature and criteria's definition and agile indices of supply chain, we provided checklists to evaluate the score of each index or criterion in Merat Misagh Mass Construction Associations (See Appendix 1). The checklists have been given to 110 experts of different parts of Merat Misagh and 95 of them were completed and analyzed by SPSS and Excel. Cronbach's Alpha test was used to test the reliability of the questionnaire. Cronbach alpha was used to validate the results first for the summary and next for the final version and they are 0.983 and 0.855 , respectively.

Since the Cronbach's Alphas are well above 0.7, indices are considered to be reliable. The final results are summarized in Table 3. The table includes the average score of checklists of agility, importance coefficient of criteria and indices resulted of paired comparison and agility measurement. In addition, the maximum rate of agility of each criteria (the multiplication of value of criteria by 5), agility ratio (agility rate divided by the sum of agility rate) and the rate of the gap (the difference between agility rate and maximum agility rate) are also presented in the table. 


\section{Table 3}

Information summery of agility of criteria measurement in Merat Misagh Mass Association

\begin{tabular}{lllllll}
\hline Criterion & Average & Weight & Agility & Maximum agility & Agility ratio & The gap \\
\hline Market & 1.88 & 0.22 & 0.42 & 1.12 & 0.21 & -0.70 \\
Technology & 1.47 & 0.21 & 0.31 & 1.06 & 0.16 & -0.75 \\
Society & 1.81 & 0.03 & 0.06 & 0.17 & 0.03 & -0.11 \\
Government & 1.34 & 0.15 & 0.20 & 0.73 & 0.10 & -0.54 \\
Information technology & 1.28 & 0.04 & 0.04 & 0.18 & 0.02 & -0.13 \\
Financial & 3.86 & 0.16 & 0.60 & 0.78 & 0.30 & -0.18 \\
Partnership & 2.22 & 0.07 & 0.16 & 0.36 & 0.08 & -0.20 \\
Quality & 1.68 & 0.12 & 0.20 & 0.60 & 0.10 & -0.40 \\
\hline Total & 15.54 & 1.00 & 2.00 & 5.00 & & 1.00 \\
\hline
\end{tabular}

According to relative importance coefficient resulted from analysis of the network and gained scores of checklist, agility for each of criterion in Merat Misagh Mass Association has been calculated. The geometric graph of agility is presented in Fig. 2, where the percentage of agility is specified related to each criterion's level.

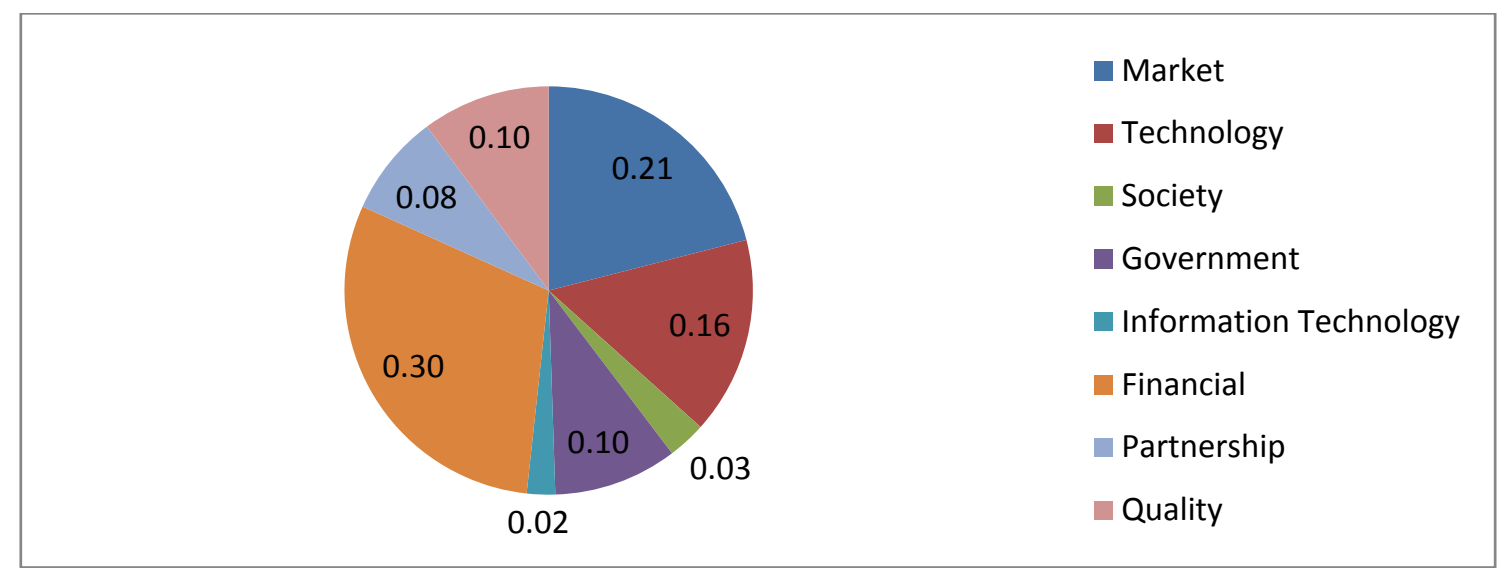

Fig. 2. Agility in criterion’s level of Merat Misagh Mass Association

The graph of gap between existing and desired criteria status of Merat Misagh Association is presented in Fig 3 where the difference of each criterion from desired agility status is shown.

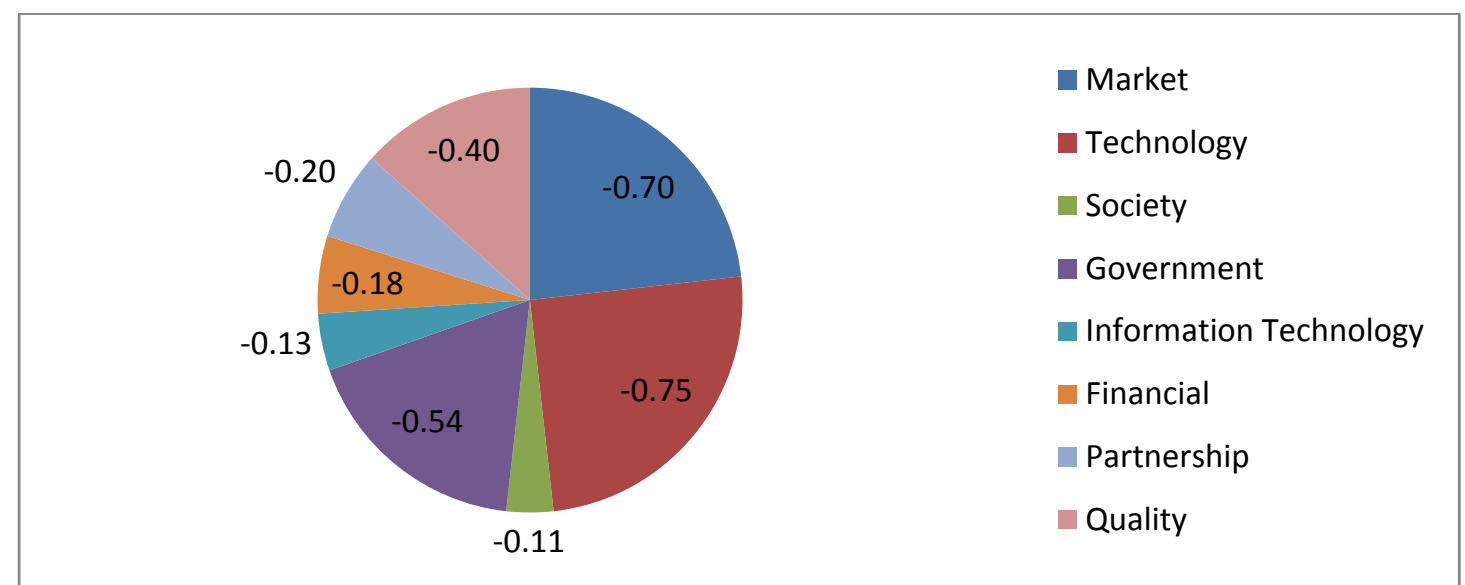

Fig. 3. The gap between existing and desired criteria status on agile criterion’s level

According to relative importance coefficients resulted of network analysis and gained score of checklists, agility for each of indices in Merat Misagh Association has been calculated. The geometric graph of agility is presented in Fig 4, where the percentage of agility is specified related to each index's level. 


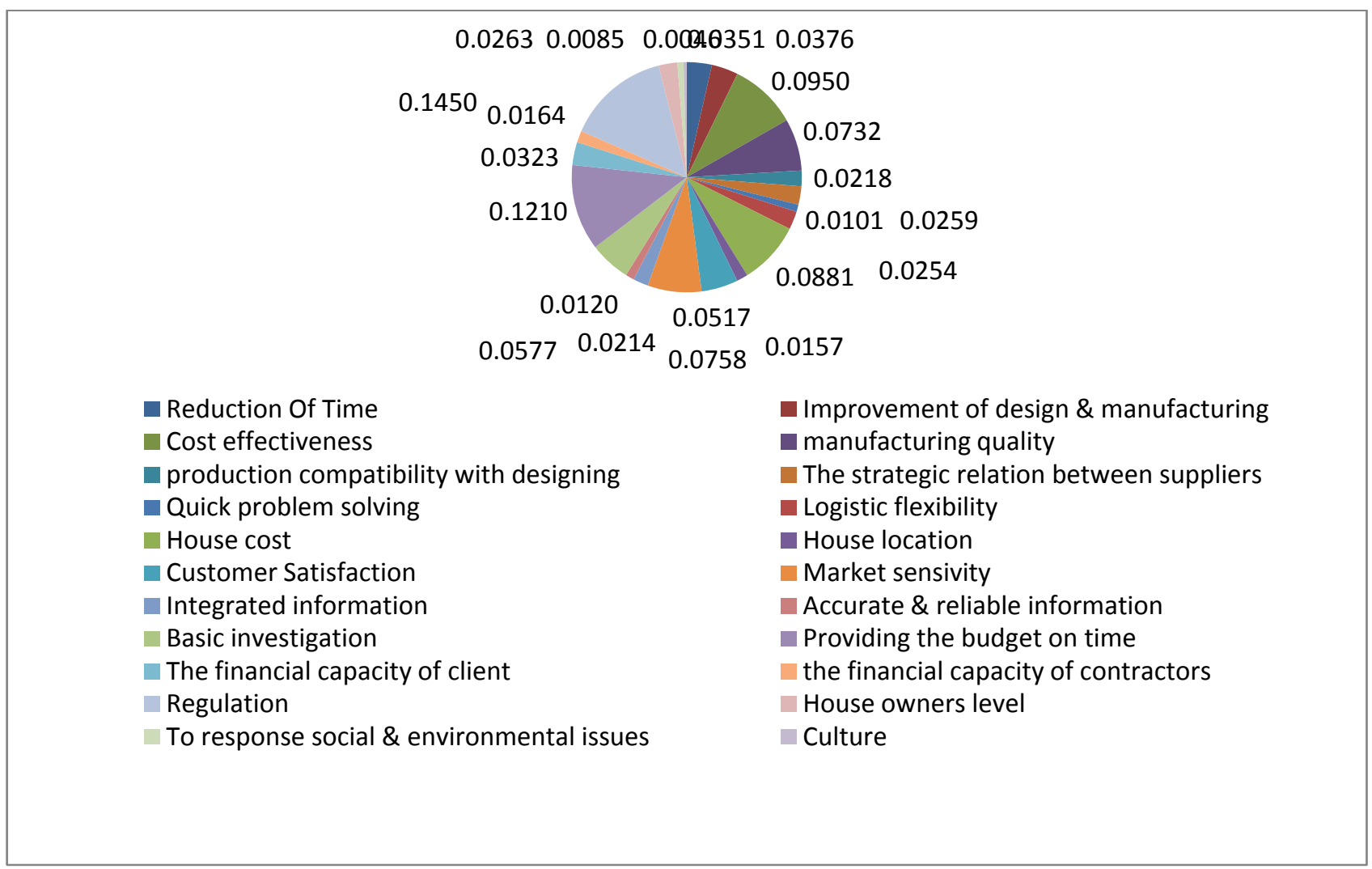

Fig. 4. Agility in index level of Merat Misagh Mass Construction Association

Finally, Fig. 5 shows the gap between existing and desired indices status of Merat Misagh Association, where the difference of each index from desired agility status is shown in this graph.
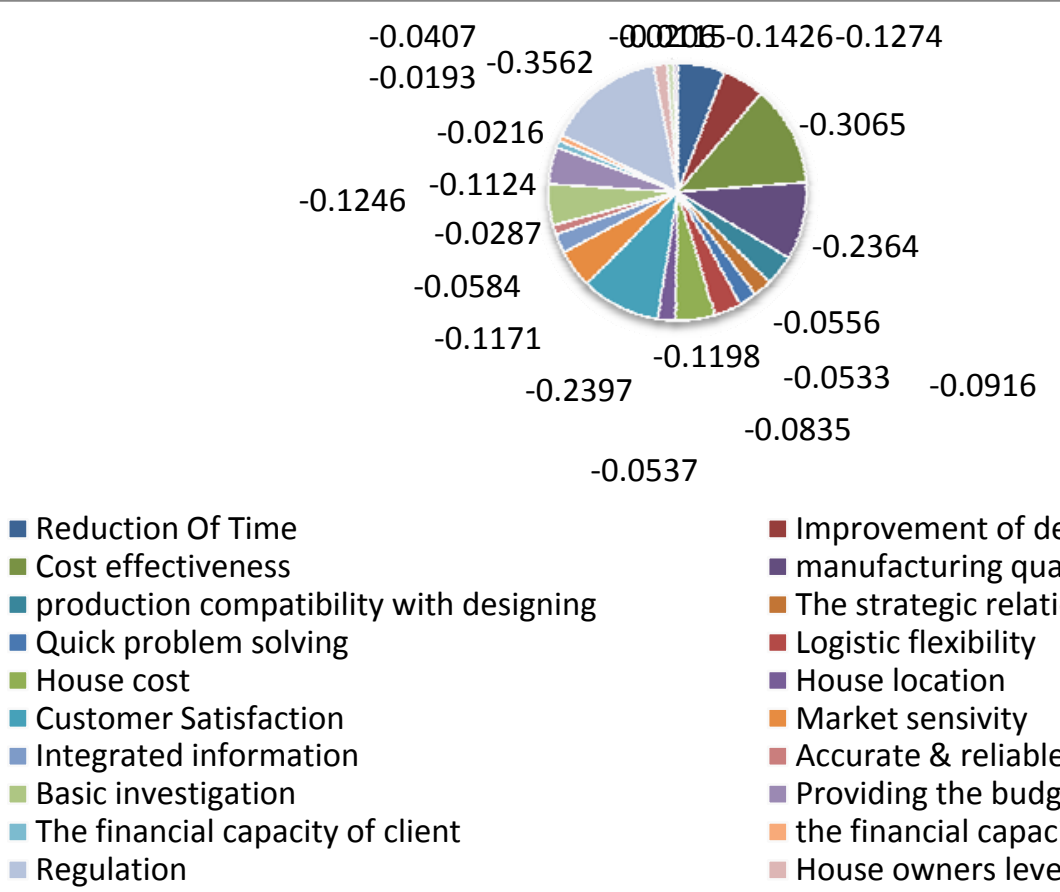

- Improvement of design \& manufacturing - manufacturing quality

- The strategic relation between suppliers

- Logistic flexibility

- House location

- Market sensivity

- Accurate \& reliable information

- Providing the budget on time

the financial capacity of contractors

House owners level

Fig. 5. The graph of gap between existing and desired criteria status on agile criterion's level 


\section{Conclusion}

It is clear that those organizations with the ability to lead the market in a changing environment must have agile supply chain. An environment with more agility results in a more agile supply chain. To be able to have an agile supply chain we should evaluate the agility first. Evaluating the agility can help us with the improvement of agility level. Findings show that having agile supply chain in companies helps improve the production, quality, flexibility, delivery and services. All these features result in having a more competitive environment.

This study shows that the agility of Merat Misagh Mass Construction Association's supply chain changes from 2 to 5 . In other words, agility of supply chain is $40 \%$. As we have explained, the highest agility score of agility is associated with "financial" while the lowest score is associated with "information technology". In addition, the highest agility score is related to "regulations" and the lowest is related to "culture" index, which means the criterion "information technology" has become a problematic issue for Merat Misagh Association. If the Association tends to improve its level and be responsible to changes of the environment, it has to pay more attention to the problematic criterion. It should be said that the priority of the indices is specified to "culture" index.

The results and findings of this study can be useful to those experts who work in changing environments and seek to make their supply chain more agile. Note that the importance of any criterion or index is different in various business atmospheres. Therefore, managers should regard different environments with different point of view. We cannot compare any mass construction association with any other or match their agility. It is possible to evaluate the supply chain's agility of other industries according to the approach introduced in this study.

\section{Acknowledgements}

The authors would like to thank the Qazvin Islamic Azad University (QIAU) and the Imam Khomeini International University of Qazvin for financial supports.

\section{References}

Agarwal A., Shankar R., \& Tiwari M.K. (2007). Modeling agility of supply chain. Industrial Marketing Management, 36, 443-445.

Agarwal A., Shankar R., \& Tiwari M.K. (2006). Modeling the metrics of lean, agile and leagile supply chain: An ANP- based approach. European Journal of Operational Research, 173(1), 211225.

Azar, A., Tizroo, A., Moghbel Baarz, A., \& Anvary Rostamy A. (2011). Modeling the agility of supply chain using interpretive structural modeling approach. Quarterly Journal Modares Human Sciences Management Research in Iran, 14(4), 1-26.

Baker, P. (2008). The design and operation of distribution centers within agile supply chain. International Journal of Production Economics, 111(1), 27-41.

Bal J., Wilding R., \& Goundry J. (1999). Virtual teaming in the agile supply chain. International Journal of Logistics Management, 10(2), 71-83.

Chiristopher, M. (2000). The agile supply chain: competing in volatile markets. Industrial Marketing Management, 29, 37-44.

Chiristopher, M., \& Towill D.R. (2002). An integrated model for the design of agile supply chain. International Journal of Physical Distribution and logistics, 31(4), 235-246.

Gunasekaran, A., Patel, C., \& McGaughey, R. (2004). A framework for supply chain performance measurement. International Journal of Production Economics, 87, 333-347.

Iacocca Institute. (1991). $21^{\text {st }}$ century manufacturing enterprise strategy; An industry Led View. Iacocca Institute, 1(2), Bethlem, PA.

Jamaes, T. (2005). Stepping back from. IEEE manufacturing engineer, 84 (1), 16-21. 
Jasbi, J., Seyed Hosseini, S.M., \& Pilehvari, N. (2010). An adaptive Neuro fuzzy inference system for supply chain evaluation. International Journal of Industrial Engineering and Production Research, 20(4), 187-196.

Kazazi, A., \& Sohrabi, R. (2010). Designing the operational attributes and criteria for supply chain agility evaluation in national Iranian oil company case of NISOC. Transformational Management Journal, 2(4), 142-165.

Kisperska- moron, D, \& Swierczek, A. (2008), the agile capabilities of polish companies in the supply chain: an empirical study. International Journal of Production Economics. 118(1), 217-224.

Maskell, B. (2001). The age of agile manufacturing. Supply Chain Management: An International Journal, 6(1), 5-11.

Poloie K., Fazli S., Alvandi M., \& Hasanlo S. (2012). A framework for measuring the supply chain's agility of mass construction industry in Iran. Management Science Letters, 2, 2317-2334.

Poloie, K. (2012). A framework for measuring agility in supply chain in Iranian mass construction industry. The thesis presented of the degree of Master of Science in management (production). Imam Khomeini International University.

Prince, J., \& Kay, J.M. (2003). Combining lean and agile characteristics: creation of virtual groups by enhanced production flow analysis, International Journal of production Economics, 85, 305-318.

Radfar, R.T., Pilevari, N., \& Aflaki S. (2011). A model for evaluating and comparing the agility of supply chain case study: Iran telecommunication company and Iraancell company. American journal of scientific research, 33, 127-135.

Rigby C., Day M., Forrester P, \& Burnett J. (2000). Agile supply: Rethinking systems thinking, Systems practice. International Journal of Agile Management Systems, 2(3), 178-186.

Svensson, G. (2001), Perceived trust towards suppliers and customers in supply chains of the Swedish automotive industry. International Journal of Physical Distribution and Logistics Management, 31(9), 647-662.

Tolon W. J. (2000). Virtual situation room: connecting people across enterprises for supply chain agility. Computer Aided Design, 32, 109-117.

Van H., \& Harrison A. (2001). Measuring agile capabilities in the supply chain. International Journal of Operation \& Production Management, 21(1/2), 71-87.

Vonderembse, M. A., Mohit Uppalb, S., Huangc, J., \& Dismuke, P. (2006). Designing supply chains towards theory development. International Journal of Production Economics, 100, 223-238.

Yusuf, Y.Y., \& Adeleye, E. O. (2002), A Comparative study of lean and agile manufacturing with related survey of current practices in the UK. International journal of production research, 40 (17), 4545-4562. 


\section{Appendix 1}

Questionnaire of measuring the agility of supply

\begin{tabular}{|l|l|l|l|l|l|}
\hline Criteria & Very weak & Weak & Average & Good & Very Good \\
\hline Market & & & & & \\
\hline Technology & & & & & \\
\hline Society & & & & & \\
\hline Government & & & & & \\
\hline Information Technology & & & & & \\
\hline Financial & & & & & \\
\hline Partnership & & & & & \\
\hline Quality & & & & & \\
\hline
\end{tabular}

Questionnaire of measuring the agility of supply chain's indices

\begin{tabular}{|l|l|l|l|l|l|}
\hline Indices & Very weak & Weak & Average & Good & Very Good \\
\hline Reduction Of Time & & & & & \\
\hline Improvement of design \& manufacturing & & & & & \\
\hline Cost effectiveness & & & & & \\
\hline manufacturing quality & & & & & \\
\hline production compatibility with designing & & & & & \\
\hline The strategic relation between suppliers & & & & & \\
\hline Quick problem solving & & & & & \\
\hline Logistic flexibility & & & & & \\
\hline House cost & & & & & \\
\hline House location & & & & & \\
\hline Customer Satisfaction & & & & & \\
\hline Market sensitivity & & & & & \\
\hline Integrated information & & & & & \\
\hline Accurate \& reliable information & & & & & \\
\hline Basic investigation & & & & & \\
\hline Providing the budget on time & & & & & \\
\hline The financial capacity of client & & & & & \\
\hline the financial capacity of contractors & & & & & \\
\hline Regulation & & & & & \\
\hline House owners level & & & & & \\
\hline To response social \& environmental issues & & & & & \\
\hline Culture & & & & & \\
\hline
\end{tabular}

